\title{
Facile Synthesis of Nitrogen - Containing Carbon by Carbonization of Furfural in Deep Eutectic Mixtures
}

\author{
XINGLIANG LI ${ }^{\mathrm{a}, b^{*}}$, BIJUN LIU ${ }^{\mathrm{a}}$, HUI TANG ${ }^{\mathrm{a}}$, LIJUAN CHEN $^{\mathrm{a}}$, MEI GU ${ }^{\mathrm{a}}$, \\ YUAN JIAN $^{\mathrm{a}, \mathrm{b}}$, ZHENGKUN ZHONG $^{\mathrm{a}}$ and SHUNZHONG LUO ${ }^{\mathrm{a}}$
}

${ }^{a}$ Institute of Nuclear Chemistry and Physics, China Academy of Engineering Physics, Mianyang, 621900, P. R. China

${ }^{\mathrm{b}}$ Institute of Nuclear Science and Technology, Sichuan University, Chengdu, 610064, China xingliang_li@163.com

Received 7 August 2012 / Accepted 12 October 2012

\begin{abstract}
Amorphous nitrogen-containing carbon was successfully prepared by carbonization of furfural in a deep eutectic mixture of urea and choline chloride. Primary amine groups were able to be anchored to the carbon in a one-pot solvothermal carbonization procedure. XPS analysis showed that nitrogen predominantly bound within the solid as well as at the surface. An abundance of functional groups on the surface of the carbon during the carbonization process generated large, graphite-like interlayer spaces. $\mathrm{N}$-doped carbon exhibits reactive surfaces because nitrogen can easily be further modified through the grafting of other chemical groups. The carbon obtained by this innovative approach may be a good matrix for solid phase extraction because of its narrow pore size.
\end{abstract}

Keywords: Carbon, Furfural, Deep eutectic mixture, Urea, Choline chloride

\section{Introduction}

Nitrogen-containing carbon materials are exciting candidates for technological and energyrelated applications, including separation, catalysis and energy storage/conversion because of their unique physicochemical properties. The preparation and properties of these materials have attracted considerable attention ${ }^{1-6}$. Chemical nitrogen can be introduced to carbon by thermal post-treatment of the respective material with different nitrogen sources, typically ammonia and, to a lesser extent, urea or nitric acid. However, the main synthesis route for $\mathrm{N}$-doped carbon with high structural nitrogen content is an in situ process that derives the $\mathrm{N}$-doped carbonaceous material directly from nitrogen-rich precursors. In situ doping of carbon using nitrogen-containing precursors permits homogeneous incorporation of nitrogen into the carbon material and several nitrogen-doped carbon materials have been prepared using this method $^{7-9}$.

In the last decade, ionic liquids (ILs) have gained great attention due to their attractive properties such as biocompatibility, high viscosity, thermal and chemical stability, negligible volatility and their ability to dissolve a wide range of solutes. ILs used as precursors for 
carbonization are either commercially available or can be easily synthesized using standard procedures. In the particular case of carbonization, ILs have been used not only as solvents but also as initiators ${ }^{10-18}$. Deep eutectic solvents (DESs) are a new class of ionic liquids obtained by the complexation of quaternary ammonium salts with hydrogen bond donors ${ }^{19-23}$. Here we describe the use of DESs of urea and choline chloride as suitable precursors for $N$-doped carbon materials. As the precursors are liquid at room temperature, they can be easily incorporated into the carbon product.

\section{Experimental}

All chemical reagents used in this work were of analytical grade purity and are commercially available. DESs based on mixtures of urea and choline chloride were prepared as previously reported ${ }^{19,20}$. In a typical experiment, urea and choline chloride were mixed in a 2:1 molar ratio and heated to $100^{\circ} \mathrm{C}$ until the solution became clear.

Furfural $(40 \mathrm{~mL})$ and the deep eutectic mixture $(40 \mathrm{~mL})$ were added into a Tefloncoated stainless steel autoclave (100 mL capacity). The autoclave was placed in a furnace, sealed and heated to the desired temperature, at which it was held for a fixed time before being allowed to cool to room temperature. Dark products were obtained by filtration. After washing several times with distilled water and ethanol, the black solids were dried in air at room temperature. An SEM image of a typical product is shown in Figure 1.

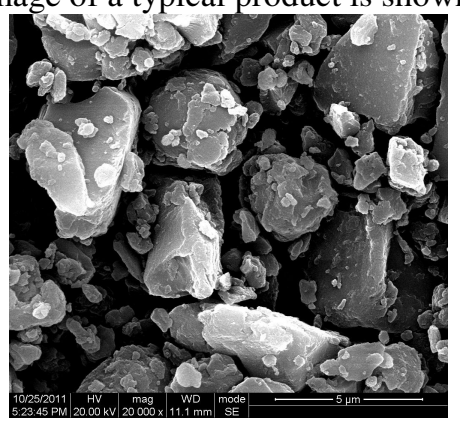

Figure 1. Typical SEM image of the N-doped carbon

Elemental analysis was performed on an Elementar Vario EL Cube analyzer. XPS measurements were conducted using a physical electronics ESCA 5600 spectrometer with a monochromatic $\mathrm{Al} \mathrm{Ka}$ X-ray source at a power of $200 \mathrm{~W} / 14 \mathrm{kv}$ and a multi-channel detector (Omni IV). Gaussian-Lorentzian curves and Shirley background were applied for photoelectron peak analysis. FT-IR analysis was performed on a Thermo Scientific Nicolet 6700 spectrometer with a SMART iTR diamond ATR accessory. Powder XRD data were obtained using an X'Pert PRO diffractometer with a $\mathrm{Cu}-\mathrm{K} \alpha$ radiation source $(\lambda=115406 \AA)$ with a step size and count time of $0.02^{\circ}$ and $2 \mathrm{~s}$, respectively. Nitrogen adsorption and desorption isotherms were measured at $77 \mathrm{~K}$ with a Beckman Coulter SA 3100 surface area analyzer. For the determination of the surface area, the BET method was used.

\section{Results and Discussion}

The elemental analysis results of the carbon materials produced under different temperatures and for different reaction times are given in Table 1 . There is only a slight difference in the $\mathrm{CHN}$ content of the product when the reaction temperature was between 150 and $160{ }^{\circ} \mathrm{C}$ and reaction time varied from 2.5 to $6.5 \mathrm{~h}$. Solid carbon could not be obtained at reaction temperatures less than $140{ }^{\circ} \mathrm{C}$. Conversely, destruction of the Teflon kettle at high pressure precluded the reaction from being conducted above $170{ }^{\circ} \mathrm{C}$. 
Table 1. CHN content in the N-doped carbon

\begin{tabular}{ccccc}
\hline \multirow{2}{*}{$\begin{array}{c}\text { Reaction } \\
\text { temperature, }{ }^{\circ} \mathrm{C}\end{array}$} & Reaction time, h & \multicolumn{3}{c}{ Element content, wt\% } \\
\cline { 3 - 5 } & & $\mathrm{H}$ & $\mathrm{N}$ & $\mathrm{C}$ \\
\hline 150 & 2.5 & 4.45 & 10.34 & 63.98 \\
150 & 4.5 & 4.96 & 10.78 & 61.23 \\
150 & 6.5 & 4.06 & 9.73 & 65.87 \\
155 & 6.5 & 4.26 & 10.13 & 66.66 \\
160 & 6.5 & 4.41 & 10.45 & 63.31 \\
\hline
\end{tabular}

XPS analysis indicates that a significant number of oxygen and nitrogen functional groups were present on the surface of the product materials. The $\mathrm{C} 1 \mathrm{~s}$ spectra have each been resolved into four individual component peaks (Figure 2), representing carbidic carbon (283.45 eV, peak 1), graphitic carbon (284.24 eV, peak 2), carbon present in the form of alcohol, amine or ether ( $285.59 \mathrm{eV}$, peak 3$)$ and carbonyl, ester or amide functional groups (287.18 eV, peak 4). The high resolution O1s spectra (Figure 2) show three peaks corresponding to alcohol or ether $(530.51 \mathrm{eV}$, peak 1$)$, ketone or carbonyl (532.65 eV, peak 2) and ester functional groups $(533.53 \mathrm{eV}$, peak 3$)$. The chemical environment of the incorporated nitrogen atoms determines the properties of the material and two different types of nitrogen can be distinguished: chemical nitrogen and structural nitrogen. The former appears as surface functionalities, such as amine or, in some cases, nitrosyl groups. The latter describes nitrogen directly bound to the backbone of the carbon material, such as pyridinic or quaternary-graphitic nitrogen. Here the N1s spectra (Figure 2) are broad and asymmetric, indicating that there are different binding configurations. From a curve deconvolution, the spectra can be well-fitted to two peaks, corresponding to pyrrolic, pyridinic or quaternary graphitic nitrogen $(398.3 \mathrm{eV}$, peak 1$)$ and amine or nitro functional groups $(401 \mathrm{eV}$, peak 2$)$. These results indicate that the nitrogen predominantly binds within the solid and not only at the surface.

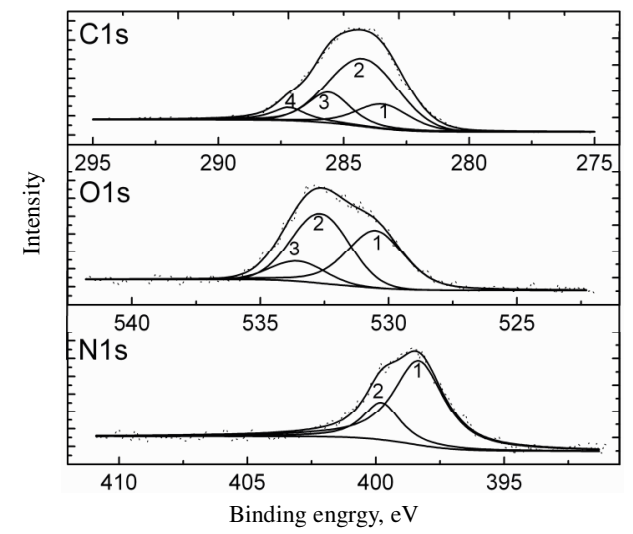

Figure 2. XPS spectra of the N-doped carbon

The presence of functional groups at the surface was also revealed by FT-IR measurements (Figure 3). The bands at $1662 \mathrm{~cm}^{-1}$ are attributed to the aromatic amide vibration, providing evidence for the oxidation of furfural during carbonization. The absorption peak at $1477 \mathrm{~cm}^{-1}$ belongs to the aromatic $\mathrm{C}=\mathrm{C}$ stretching vibration. The bands at $1079 \mathrm{~cm}^{-1}$ can be attributed to the $\mathrm{C}-\mathrm{O}-\mathrm{C}$ stretching vibration and imply the existence of ether groups. The sharp, narrow and intense bands at $730 \mathrm{~cm}^{-1}$ result from the asymmetric $\mathrm{CH}_{2}$ rocking vibration of the hydrocarbon. When the adsorption peaks are compared, it is 
clear that the FT-IR spectra of the carbon materials obtained at different temperatures and reaction times are almost the same. Straightforward chemical modification of carbon, such as grafting other chemical groups to the carbon surface, is possible because of these functional groups ${ }^{24-26}$.

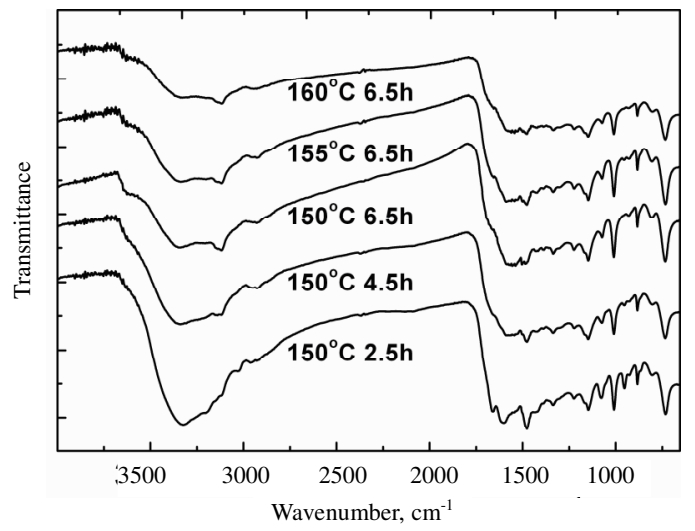

Figure 3. FT-IR spectra of the $N$-doped carbon

The powder XRD patterns of the carbon materials are shown in Figure 4(A). A broad diffraction peak at a $2 \theta$ value of $21^{\circ}$ is characteristic of the 002 plane of graphitic carbon. However, the width of the diffraction peaks is different from pure graphite and indicates the presence of amorphous carbidic carbon. The position of the diffraction peaks associated with the 002 plane shifts to a lower $2 \theta$ value in these materials, due to the oxidation of the surface layer having generated a larger interlayer space during carbonization.
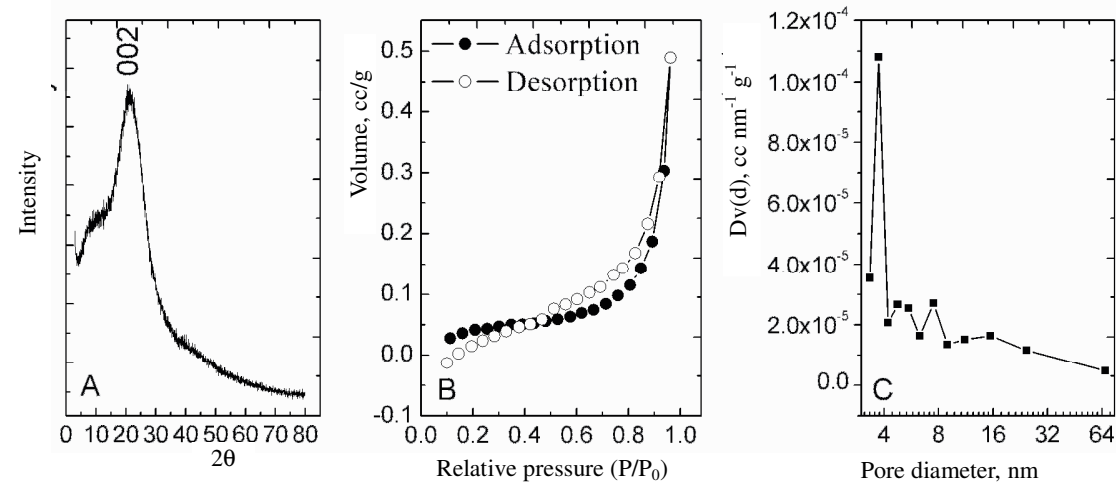

Figure 4. XRD spectrum (A), adsorption isotherm (B) and pore size distribution (C) of the $\mathrm{N}$-doped carbon

Figure 4(B) shows the nitrogen adsorption-desorption isotherms of the carbon materials. The isotherm shows a pronounced capillary condensation in the relative pressure range of $0.8-1.0$, corresponding to the existence of mesopores with a narrow pore size distribution centered at $3.7 \mathrm{~nm}$ (Figure 4 (C)). We have found that the affinity and selectivity of a solid phase extractant for uranium ions in an active carbon support could be increased by a reduction in the pore size in the carbon matrix ${ }^{27}$. Compared with active carbon, the nitrogencontaining carbon obtained in this study exhibits a narrower pore size. Thus, these nitrogencontaining carbon products are good candidates for solid phase extractant supporting materials. Further study in this area is currently underway. 


\section{Conclusion}

A one-pot approach towards producing functionalized nitrogen-containing carbon has been developed through the carbonization of furfural in deep eutectic mixtures of urea and choline chloride. Spectroscopic data (FTIR, XPS) indicated that a significant number of functional groups were present on the surface of the carbon materials. These functional groups can be used to graft further functional moieties to the carbon materials, for example, by oxidation or substitution of functional groups containing heteroatoms, such as $\mathrm{N}$ and $\mathrm{S}$. Moreover, these materials can be used in solid phase extraction. This is a positive outcome in terms of green chemistry and provides a simple and economical method for the development of new carbon materials.

\section{References}

1. Xiao C, Chu X, Yang Y, Xing Li, Xiaohua Zhang and J Chen, Biosens Bioelectron., 2011, 26(6), 2934-2939.

2. Pérez-Cadenas M, Moreno-Castilla M, Carrasco-Marín F and Agustín F PérezCadenas, Langmuir, 2009, 25(1), 466-470.

3. Wang L and Yang R, J Phys Chem C, 2009, 113(52), 21883-21888.

4. Gorgulho H F, Gonçalves F, Pereira M F R and José L. Figueiredo, Carbon, 2009, 47(8), 2032-2039.

5. Shen M-R, Gan Z-Q and Ge S-B, Yu Xin and Ming-Rong Ji, Thin Solid Film, 1999, 339(1-7), 34-37.

6. Maiyalagan T and Viswanathan B, Mater Chem Phys., 2005, 93(2-3), 291-295.

7. Lahaye J, Nansé G, Bagreev A and V Strelko, Carbon, 1999, 37(4), 585-590.

8. Rozlívková Z, Trchová M, Exnerová M and Jaroslav Stejskal, Synth Met., 2011, 161(11-12), 1122-1129.

9. Jia Y F, Xiao B and Thomas K M, Langmuir, 2002, 18(2), 470-478.

10. Yuan J, Márquez A G, Reinacher J, Cristina Giordano, Jürgen Janek and Markus Antoniett, Polym Chem., 2011, 2, 1654.

11. Kuhn P, Forget A and Hartmann J, Arne Thomas and Markus Antonietti, Adv Mater., 2009, 21(8), 897-901.

12. Wang X and Dai S, Angew Chem., 2010, 122(37), 6814-6818.

13. Lee J S, Mayes R T, Luo H and Sheng Dai, Carbon, 2010, 48(12), 3364-3368.

14. Lee J S, Wang X, Luo H, Gary A Baker and Sheng Dai, J Am Chem Soc., 2009, 131(13), 4596-4597.

15. Yuan J, Giordano C and Antonietti M, Chem Mater., 2010, 22(17), 5003-5012.

16. Bojdys M J, Müller J O, Antonietti M and Arne Thomas, Chem Eur J., 2008, 14(27), 8177-8182.

17. Paraknowitsch J P, Zhang J, Su D, Arne Thomas and Markus Antonietti, Adv Mater., 2010, 22, 87-92.

18. Lee J S, Wang W, Luo H and Sheng Dai, Adv Mater., 2010, 22(9), 1004-1007.

19. Abbott A P, Capper G, Davies D L, Raymond K Rasheed and Vasuki Tambyrajah, Chem Commun., 2003, 39, 70-71.

20. Abbott A P, Boothby D, Capper G, David L Davies, and Raymond K Rasheed, J Am Chem Soc., 2004, 126(29), 9142-9147.

21. Gutiérrez M C, Rubio F, Monte F D, Chem Mater., 2010, 22(9), 2711-2719.

22. Carriazo D, Gutiérrez M C, Ferrer M L and Francisco del Monte, Chem Mater., 2010, 22(22), 6146-6152. 
23. Mota-Morales J D, Gutiérrez M C, Sanchez I C, Gabriel Luna-Bárcenas and Francisco del Monte, Chem Commun., 2011, 47, 5328-5330.

24. Zhao Y, Liu C, Feng M, Zhen Chen, Shuqiong Li, Gan Tian, Li Wang, Jingbo Huang and Shoujian, J Hazard Mater., 2010, 176(1-3), 119-124.

25. Tian G, Geng J, Jin Y, Chunli Wang, Shuqiong Li, Zhen Chen, Hang Wang, Yongsheng Zhao and Shoujian Li, J Hazard Mater., 2011, 190(1-3), 442-450.

26. Chen Z, Ma L, Li S, Junxia Geng, Qiang Song, Jun Liu, Chunli Wang, Hang Wang, Juan Li, Zhi Qin and Shoujian Li, Appl Surf Sci., 2011, 257(20), 8686-8691.

27. Li X, Song Q, Liu B, Liu Chunxia, Wang Hang, Geng Junxia, Chen Zhen, Liu Ning and Li Shoujian, Prog Chem., 2011, 23(7), 1446-1453. 